a percentage is calculated from this total for each division and related group. The allocation is then made by assigning each division of the program committee a base number of three panels, and apportioning the remaining panels on the basis of the percentage figure. Related group allocations are made by assigning each group a base of one panel and apportioning the remaining panels proportionate to attendance at their panels the previous year.

Beginning with the 2010 meeting, accord- ing to Council policy, no related group's allocation will exceed the median allocation of official program divisions. This means that in 2011, no related group's allocation can exceed 12 panels.

The last step is a relatively new step for program divisions. In 2008, the Council ended the bonuses distributed to divisions associated with targeted fields of interest. Instead, $10 \%$ of panels available to the program committee are distributed to divisions adjusted by their acceptance rates. Divisions with acceptance rates below the mean acceptance rate ( $15 \%$ in 2011) share in the additional panels in proportion to their distance from the mean.

In the end, the multi-step process was designed and applied to guarantee a fair distribution of a limited resource. Periodic adjustments have been and will continue to be made to the process to preserve fairness and adapt to changing conditions.

\title{
Nominations and Expressions of Interest Sought for Editor of American Political Science Review
}

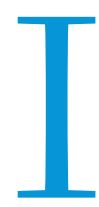
n June 2012, the UCLA editorial team at the American Political Science Review will complete its current term. President Carole Pateman has named an APSR search committee to help identify a successor or successors to be presented for Council approval in August 2011.

The members of the search committee are: John Aldrich, Duke University; Charles Beitz, Princeton University; Janet M. BoxSteffensmeier, Ohio State University; Valerie Bunce, Cornell University; Pradeep Chhibber, University of California, Berkeley; Neta Crawford, Boston University; Gary Goertz, University of Arizona; Gary Segura, Stanford University; and Joan Tronto, University of Minnesota, chair.

The Review is the centerpiece of the association's publications. Its contents represent the best work in political science to political scientists in the United States and abroad, other social scientists, and interested parties in foundations, government, and the private sector.

The search committee invites nominations and proposals for an editor or group of editors to lead the Review. The new editor or editors will be charged with maintaining the centrality of the Review to the profession and upholding the standards of excellence cultivated by Review editors since 1906 . The search committee seeks an editor or editorial team that has a commitment to publishing articles that represent the methodological and substantive diversity of the discipline, including qualitative and multi-method research. Any proposal should include ideas for maintaining the high standards of the journal and increasing the diversity of articles that are published.

Typically, the cost of running the journal is shared by the editor(s)' home institution and the APSA. Nominators and potential editors should consider this situation in making nominations and proposals to the committee. The association is especially open to proposals that include innovative individual and institutional collaborations, and it welcomes preliminary discussions with candidates about how such proposals might be structured and funded.

Nominations and expressions of interest, accompanied by a resume(s), should be sent to APSA Executive Director Michael Brintnall. The committee will begin to review received nominations and proposals on February 16,2011 . The committee may review proposals submitted after the deadline. Proposals submitted on or before the deadline will certainly receive full consideration. 